REVESCO. Revista de Estudios Cooperativos

ISSN: $1885-8031$

\title{
La sostenibilidad de la vivienda: razones para incentivar su desarrollo en España ${ }^{1}$
}

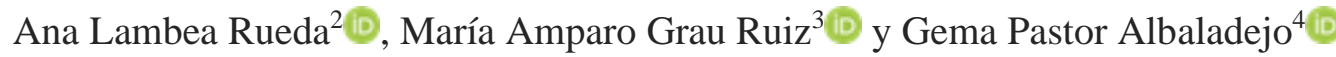

Recibido: 11 de julio de 2019 / Aceptado: 28 de enero de 2020 / Publicado: 16 de marzo de 2020

Resumen. En el marco de los Objetivos de Desarrollo Sostenible de la Agenda 2030 (en particular en el Objetivo número 11 sobre Ciudades y Comunidades Sostenibles) se aprobó la Directiva 2018/844 UE de 30 de mayo, modificando las anteriores 2010/31 de eficiencia energética de edificios y 2012/27 de eficiencia energética, para lograr "un parque inmobiliario descarbonizado y altamente eficiente (...) para transformar los edificios existentes en edificios de consumo de energía casi nulo... con una renovación a una tasa media anual del 3\% (...) aplicando las Directrices de la OMS sobre la calidad de aire interior... y apoyando medidas de fomento de financiación inteligente para edificios inteligentes de la Comisión Europea".

La Directiva anuncia una mejora de la transparencia de los certificados de eficiencia energética, garantizando el establecimiento y la aplicación uniformes de todos los parámetros de cálculo necesarios, tanto por lo que respecta a la certificación como a los requisitos mínimos de eficiencia energética, y propone un sistema de control posterior automatizado y electrónico.

En el marco del proyecto del Plan nacional de I+D+i CertificaRSE ${ }^{5}$, se han analizado la certificación, las eco-etiquetas y el apoyo necesario con recursos financieros públicos para impulsar el futuro del sector. Para obtener esta información, se ha optado por diseñar y aplicar una técnica de investigación cuantitativa. En concreto, se ha realizado una encuesta a los grupos de interés del sector de la edificación y rehabilitación, por su experiencia con el manejo de certificaciones y su impacto real en la sostenibilidad.

Se ha invitado a los encuestados a valorar la introducción de nuevos incentivos en los impuestos aplicables al sector de construcción y rehabilitación de viviendas, ajustados al retorno en sostenibilidad que generan, con el propósito de mejorar la normativa y la comunicación de todos los agentes involucrados con la sociedad. La finalidad de esta encuesta ha sido valorar la adecuación del marco normativo y financiero a la hora de atender las necesidades existentes, por lo que se han tenido en cuenta diferentes dimensiones analíticas: la sostenibilidad en el sector, la certificación, los recursos económicos y financieros, la normativa aplicada y la comunicación con agentes del sector y con la sociedad.

Palabras clave: Sostenibilidad; Vivienda; Rehabilitación; Certificación; Incentivos fiscales.

Claves Econlit: P18; L38; Q01; K25; K34; K00; H21; H22.

\section{[en] The sustainability of housing: reasons to encourage its development in Spain}

Abstract. In the framework of the Sustainable Development Goals of the 2030 Agenda, in particular Goal 11 on Sustainable Cities and Communities, the EU Directive 2018/844 of May 30 was approved, modifying the previous 2010/31 buildings energy efficiency and 2012/27 energy efficiency, to achieve "a decarbonized and highly efficient buildings' stock ... to transform existing buildings into buildings with almost zero energy consumption ... with a renovation at an average annual rate of $3 \%$... applying the WHO Guidelines on indoor air quality ... and supporting measures to promote smart financing for smart buildings of the European Commission ".

The Directive announces an improvement in the transparency of energy efficiency certificates, guaranteeing the uniform establishment and application of all the necessary calculation parameters, both in terms of certification and minimum energy efficiency requirements, and proposes an automated and electronic back control system.

In the CertificaRSE Project, within the national Plan of R\&D+i, the certification, the eco-labels and the necessary support with public funding to promote the future of this sector. A choice has been made, since the early stage of this Project, to use a quantitative research technique. We have conducted a survey to different stakeholders in the field of buildings and their renovation, given their expertise in the use of certificates and the actual impact on sustainability.

The introduction of new incentives has been valued in the taxes applicable to the housing construction and rehabilitation sector, adjusted to the return in sustainability that they generate, with the purpose of improving the regulations and the

1 Proyecto Retos del Plan Nacional de I+D+i CertificaRSE. Efectos jurídico-financieros y control del impacto social para el desarrollo sostenible: el papel de las certificaciones en las inversiones y la contratación pública (DER2015-65374-R).

2 Universidad Complutense de Madrid, España

Dirección de correo electrónico: alambear@ucm.es.

Universidad Complutense de Madrid, España

Dirección de correo electrónico: grauruiz@ucm.es.

4 Instituto Complutense de Ciencia de la Administración, España

Dirección de correo electrónico: gpastora@ucm.es.

http://www.oecd.org/env/tools-evaluation/thecostofairpollution.htm. 
communication of all the agents involved with society. The purpose of this survey has been to assess the adequacy of the regulatory and financial framework when dealing with existing needs. For this, the survey has been structured in several analytical dimensions (sustainability in the sector, certification, financial resources, regulations and communication to society).

Keywords: Sustainability; Housing; Rehabilitation; Certification; Tax incentives.

Sumario. 1. Introducción. 2. La necesidad de este debate. 3. Fundamentos normativos y relevancia de los objetivos perseguidos. 4. Hipótesis y metodología. 5. Resultados. 6. Conclusiones. 7. Referencias bibliográficas.

Cómo citar: Lambea Rueda, A.; Grau Ruiz, M.A.; Pastor Albaladejo, G. (2020) La sostenibilidad de la vivienda: razones para incentivar su desarrollo en España. REVESCO. Revista de Estudios Cooperativos, vol. 133, e67334. https://dx.doi.org/10.5209/REVE.67334.

\section{Introducción}

En la situación actual deben investigarse los factores que inciden en el desarrollo de la vivienda.

La vivienda es un bien preciado, podría considerarse de primera necesidad, aunque, en las últimas décadas, se ha convertido en un objetivo de inversión y consumo. Por ello, debemos replantearnos el futuro de la misma, combinando la necesidad del que utiliza y los intereses de quien promueve y construye, dentro del marco de los Objetivos de Desarrollo Sostenible de Naciones Unidas.

Por otra parte, en el ámbito inmobiliario, el sector ha experimentado una profunda crisis desde la década de los años 2000 hasta nuestros días. Dicha crisis ha sacado a la luz una demanda y una oferta insatisfechas, y una incapacidad real de encuentro entre ambas.

También la promoción de la sostenibilidad debe ser objeto de reflexión. En particular, en los últimos años, y en parte debido a la crisis ${ }^{6}$, el sector inmobiliario se ha reorientado en torno a objetivos nuevos, entre ellos, la rehabilitación del parque de viviendas existente, para el cumplimiento de los ODS y de las Directivas Europeas de eficiencia energética. Sin embargo, dado el escaso cumplimiento de dichas normas en nuestro país, es importante plantearse: ¿qué dirección debe seguirse?, ¿son suficientes las pautas legales?, ¿debe introducirse algún cambio? El compromiso con los ODS debe ser inequívoco, y la normativa europea sobre la eficiencia energética de los edificios también es de aplicación obligada. Por ello, si el legislador (internacional, comunitario y nacional) centra la actividad inmobiliaria (presente y futura) en el desarrollo de los ODS, es importante incidir no sólo en las cuestiones técnicas (altura, aislamiento y orientación de los edificios, fuentes de energía, zonas verdes, servicios públicos, etc.), sino también en las reglas y los requisitos que pueden contribuir a su fomento.

Por ello, es necesario orientar la legislación ${ }^{7}$ (Vargas, Gadea y Sacristán, 2015: 141; Gadea, Aixabal e Izquierdo, 2014: 104), la construcción y la rehabilitación de viviendas (Berrocal, 2013: 969) para lograr un resultado óptimo en materia de sostenibilidad y eficiencia. Este artículo pretende analizar la adecuación del marco normativo y financiero a la hora de atender las necesidades existentes, en varias cuestiones fundamentales: la sostenibilidad, la certificación, los recursos financieros, la normativa y la comunicación a la sociedad.

En materia de sostenibilidad y eficiencia, puede y debe destacarse que las Cooperativas de viviendas de construcción o rehabilitación (Lambea 2015: 121, 2018: 1231) ${ }^{8}$ ofrecen una solución interesante para la consecución de dichos objetivos (Merino y Extezarreta 2014: 115) ${ }^{9}$, constituyéndose tanto sobre

6 Crisis importante que ha llevado incluso a un replanteamiento de la estructura societaria de promotores y constructores para contribuir a su relanzamiento: Benito Hernández, S.; Zúñiga Durán, M.O. (2010) La inseguridad jurídica para los acreedores de las Sociedades Anónimas laborales ante el Real Decreto Ley 10/2008 de 12 de diciembre: mención a las sociedades constructoras y promotoras. REVESCO N 102 , p. 76.

7 Vargas Vasserot, C., Gadea Soler, E., Sacristán Bergia, F. (2015) Derecho de las sociedades cooperativas. Madrid: La Ley; Gadea Soler, E., Atxabal Rada, A.e Izquierdo Muciño, M.E. (2014) Las cooperativas como alternativa económica: una visión de México y España. Madrid: Dykinson; Berrocal Lanzarot, A.I. (2013) Análisis de la Ley 8/2013, de 26 de junio, de rehabilitación, regeneración y renovación urbanas. Actualidad Civil, № 9, p. 969-1031.

8 Con posterioridad a 2013, en materia específica de cooperativas de viviendas, pueden consultarse: VVAA (2013) 40 años de historia de las empresas de participación. Dir. LejarriagA, G.; Muñoz García, A. ED. VERBUM; VVAA (2013) Economía social y derecho. Problemas jurídicos actuales de las empresas de economía social. Dir./coord.: Gómez Manresa, F.; Pardo López, M. COMARES, Granada; VVAA (2014) Las cooperativas de viviendas en la comunidad valenciana. Fajardo García, G. (Coord.). ED. CIRIEC España/Generalitat Valenciana; Lambea Rueda, A. (2015) Rehabilitación, Regeneración y Renovación urbana. Experiencias novedosas en Cooperativas de viviendas: rehabilitación y mediación. Rev. Jurídica CIRIEC 26, pág. 121-156; (2015) Función social de la propiedad y nuevos límites a la Propiedad Horizontal: Efectos de la normativa de rehabilitación del sector inmobiliario. Rev. Derecho Privado; (2018) Tendencias presentes y futuras de ciudades y comunidades sostenibles y viviendas colaborativas a través de plataformas digitales. RCDI 767, p. 1231-1285.

9 Merino, S. y Extezarreta, A. (2014) Las cooperativas de vivienda como alternativa al problema de la vivienda en la actual crisis económica. REVESCO No 113, p. 115: "Como consecuencia de las políticas públicas de apoyo y fomento de la rehabilitación, en muchas se han empezado a desarrollar por los socios titulares de las viviendas y/o locales cooperativas para la gestión conjunta de la rehabilitación de estos inmuebles. En el ámbito vasco se están actualmente estudiando proyectos locales de recuperación de cascos históricos utilizando la cooperativa como instrumento jurídico adecuado para ello. Así mismo, es habitual la constitución de sociedades cooperativas por vecinos de inmuebles para acometer determinadas obras bajo fórmula empresarial y no a través de su propiedad horizontal". 
cooperativas de viviendas existentes, viviendas ya construidas, que amplían su objeto (Lucas, 2017: 6) ${ }^{10}$; como sobre cooperativas de rehabilitación de viviendas de nueva creación, logrando la gestión de rehabilitación de viviendas, bloques o urbanizaciones e incluso barrios en régimen cooperativo. La razón fundamental de dicho interés es que las ayudas a la sostenibilidad precisan un apoyo empresarial que conforme el interés del colectivo de viviendas afectado. No pueden concurrir a dichas ayudas los propietarios de las viviendas individualmente, como personas físicas, ni las comunidades de propietarios en régimen de propiedad horizontal, que no tienen personalidad jurídica. Así pues, se requiere una persona jurídica que reúna dichos intereses y pueda colaborar al desarrollo de un proyecto colectivo. Las Cooperativas de rehabilitación de viviendas son personas jurídicas, son empresas de Economía Social, por lo que responden al interés de los socios, y pueden constituirse al amparo de la normativa cooperativa (Milà, 2014: 1; Pastor del Pino, 2016: 28; Aguiar, 2016: 10) ${ }^{11}$. Por tanto, se caracterizan por ser uno de los agentes más cualificados para el desarrollo de la actividad de rehabilitación de viviendas, como la realidad está demostrando.

En la actualidad, se impulsa la gestión de la rehabilitación de edificios de forma individual o en grupos, constituidos como habitualmente como cooperativa de rehabilitación, aunque puede buscarse el amparo de otras fórmulas. Se tiende hacia modelos basados en la eficiencia y viabilidad, con ahorros en la actuación (retornos) que se convierten en ingresos y hacen posible la rehabilitación. En otros países se presentan también como fórmula de desarrollo ${ }^{12}$.

\section{La necesidad de este debate}

El Tribunal de Cuentas de la Unión Europea lanzó la alerta en septiembre 2018 13: "la salud de los ciudadanos europeos no está suficientemente protegida". En su primer informe sobre la contaminación del aire, este organismo calificaba como "poco exigente" la actual legislación comunitaria ante "el mayor riesgo medioambiental" que afronta el continente. La gravedad de este problema se ha puesto de relieve también por la OCDE, al identificar no sólo sus costes, sino también las herramientas económicas que pueden emplearse para solventarlo ${ }^{14}$.

Un reciente estudio en el European Heart Journal afirma que la contaminación atmosférica podría estar causando el doble de muertes de lo que se pensaba. Además, investigadores de la Universidad de Maguncia (Alemania) estiman en casi 800.000 las muertes prematuras cada año en toda Europa, lo que representa una reducción media de dos años en la esperanza de vida para cada país. La mayoría de estos fallecimientos (entre un $40 \%$ y un $80 \%$ ) serían el resultado de enfermedades cardiovasculares, lo que significa que el impacto de la contaminación ambiental es mayor en el corazón y el aparato circulatorio que en los pulmones. Los impactos en la salud atribuibles a la contaminación del aire en Europa son sustancialmente más altos de lo que se suponía anteriormente ${ }^{15}$.

10 "Será común que la creación y gestión de comunidades de covivienda se produzcan en entornos que no se extinguen con la entrega de la vivienda (como es el caso habitual de las cooperativas de vivienda), sino que se prolongan en el tiempo para gestionar el proyecto. Tales entes gestores se encuentran en muchos casos especialmente beneficiados por la normativa estatal o de otros entes territoriales, lo cual conllevará ciertas particularidades en el ámbito fiscal": Lucas Durán, M. (2017) Aspectos tributarios del cohousing o co-vivienda. CIRIEC-España. Revista Jurídica, № 31 , pág. 6.

11 Como afirma Milà, R. (2014) Promoción inmobiliaria, autopromoción y cooperativas de viviendas. Navarra: Thomson Reuters-Aranzadi, pág. 1 y ss., es uno de los posibles objetos de la cooperativa de viviendas, aún no demasiado desarrollado. Además, como destaca Pastor del Pino M.C. (2016) Las cooperativas como sujetos de protección fiscal. CIRIEC-España. Revista Jurídica, № 28, pág. 28: "Resulta indudable que las sociedades cooperativas desarrollan tanto por su objeto como por su forma de funcionamiento una importante función social, colaborando eficazmente en la consecución de ciertos objetivos constitucionales como el del pleno empleo, el acceso a la vivienda digna, o la mejora de la cohesión social y territorial. En la medida en que la consecución de estos objetivos puede lograrse mediante adecuadas políticas de estímulo fiscal, quedarían legitimadas aquellas actuaciones tributarias que trataran de incentivarlos" [El subrayado es nuestro]. Para una revisión doctrinal de la justificación del otorgamiento de beneficios fiscales a las cooperativas, puede consultarse el artículo de Aguiar, N. (2015) Princípios cooperativos e benefícios fiscais. CIRIEC-España. Revista Jurídica, № 27, pág. 10.

12 Especialmente relevante es el caso de Italia, con experiencias variadas y exitosas de rehabilitación en régimen cooperativo: http://www.viviendacooperativa.eu/2014/05/08/experiencia-italiana-de-rehabilitacion-de-viviendas-cooperativas/. En Francia también sería posible utilizarlas con arreglo a la Ley $N^{\circ} 47-1775$ de fecha 10 de septiembre 1947 modificada por la Ley $N^{\circ} 92-643$ de 13 de julio de 1992 (http://ec.europa.eu/enterprise/policies/sme/business-environment/files/annexes_accounting_report_2011/france_en.pdf). En Portugal, la rehabilitación es posible como objeto de la cooperativa de construcción, conforme al art. 2 del Decreto-Ley No $502 / 99$ de 19 de noviembre. En otros países se avanza en general en la fórmula cooperativa, como son los casos de México (Robles e Izquierdo, 2014: 72) y de Argentina (Ortale, 2014).

13 https://academic.oup.com/eurheartj La carga de enfermedades cardiovasculares debida a la contaminación del aire ambiente en Europa se reevaluó utilizando nuevas funciones de relación de riesgo Jos Lelieveld Klaus Klingmüller Andrea Pozzer Ulrich Pöschl Mohammed Fnais Andreas Daiber Thomas Münzel

European Heart Journal, Vol. 40, No 20, 21 de mayo de 2019, pág. 1590-1596, https://doi.org/10.1093/eurheartj/ehz135.

14 https://www.elmundo.es/ciencia-y-salud/salud/2019/03/12/5c8783ea21efa0bf048b4584.html.

15 La Resolución 70/1, de 25 de septiembre de 2015, aprobó la Agenda 2030 para el desarrollo sostenible con los 17 objetivos ODS y las 169 metas de desarrollo. http://unfccc.int/portal espanol/items/3093.php. 
Este riesgo no es sólo exclusivo de las grandes ciudades, "en España hay un problema con las poblaciones de tamaño intermedio, donde existen menos mediciones y en las que un gran porcentaje de partículas son de origen doméstico o residual, por ejemplo, de calefacciones de leña".

Xavier Querol, experto del CSIC, señala que Europa se encuentra con un problema, ya que" "difícilmente se podrán bajar los umbrales si no se están cumpliendo los actuales", por lo que "se corre el riesgo de que existan dos Europas en materia de calidad de aire"16.

\section{Fundamentos normativos y relevancia de los objetivos perseguidos}

\subsection{Objetivos de Desarrollo Sostenible de Naciones Unidas}

Después del fracaso inicial de la primera cumbre sobre desarrollo sostenible, Naciones Unidas aprobó los objetivos para paliar la injusticia social, la pobreza, las desigualdades y las catástrofes medioambientales en el año 2012. Estos objetivos se vieron reforzados con el acuerdo de París sobre el clima de 2015, con previsión de aplicabilidad para el $2020^{17}$.

En lo referente al sector inmobiliario, el objetivo 11 de la Agenda 2030 de las Naciones Unidas expresamente hace referencia a las ciudades y comunidades sostenibles ${ }^{18}$, aunque todos los demás objetivos también tienen conexiones con el sector inmobiliario ${ }^{19}$.

Desde el punto de vista de la sostenibilidad global (energía, alimentación, salud, educación, etcétera) es necesario un cambio de rumbo en la actividad inmobiliaria, mediante la generación de una visión a largo plazo de la construcción, el mantenimiento y el uso de la vivienda. Los objetivos exigidos para lograr ciudades y comunidades sostenibles son: 1. Mejora de las condiciones materiales que inciden en la disminución de la pobreza, y la elevación de las condiciones y duración de la vida de los sujetos que viven en ella: condiciones técnicas de la edificación; 2. Colaborar con la inclusión social y la justicia (acceso a la vivienda de los colectivos desfavorecidos, condiciones de accesibilidad de la edificación para personas dependientes); 3. Cumplir con una construcción segura, que permita la supervivencia, una construcción que

16 http://www.undp.org/content/undp/es/home/sustainable-development-goals.html: 11. Ciudades y comunidades sostenibles: "Más de la mitad de la población mundial vive hoy en zonas urbanas. En 2050, esa cifra habrá aumentado a 6.500 millones de personas, dos tercios de la humanidad. No es posible lograr un desarrollo sostenible sin transformar radicalmente la forma en que construimos y administramos los espacios urbanos.

El rápido crecimiento de las urbes en el mundo en desarrollo, en conjunto con el aumento de la migración del campo a la ciudad, ha provocado un incremento explosivo de las mega urbes. En 1990, había 10 ciudades con más de 10 millones de habitantes en el mundo. En 2014 , la cifra había aumentado a 28 , donde viven en total cerca de 453 millones de personas.

La extrema pobreza suele concentrarse en los espacios urbanos y los gobiernos nacionales y municipales luchan por absorber el aumento demográfico en estas áreas. Mejorar la seguridad y la sostenibilidad de las ciudades implica garantizar el acceso a viviendas seguras y asequibles y el mejoramiento de los asentamientos marginales. También incluye realizar inversiones en transporte público, crear áreas públicas verdes y mejorar la planificación y gestión urbana de manera que sea participativa e inclusiva".

17 Metas en 2020, 2025 o 2030, según los casos:

Erradicación de la pobreza: 1.4. (...) derechos a los recursos económicos y acceso a los servicios básicos, la propiedad y el control de la tierra y otros bienes, la herencia, los recursos naturales, las nuevas tecnologías apropiadas y los servicios financieros, incluida la microfinanciación (...).

Vida sana: 3.4. (...) promover la salud mental y el bienestar (...) 3.9 (...) considerablemente el número de muertes y enfermedades causadas por productos químicos peligrosos y por la polución y contaminación del aire, el agua y el suelo.

Gestión del agua: 6.3.(...) mejorar la calidad del agua reduciendo la contaminación, eliminando el vertimiento y minimizando la emisión de productos químicos y materiales peligrosos, reduciendo a la mitad el porcentaje de aguas residuales sin tratar y aumentando considerablemente el reciclado y la reutilización sin riesgos a nivel mundial 6.4 (...)aumentar considerablemente el uso eficiente de los recursos hídricos en todos los sectores y asegurar la sostenibilidad de la extracción y el abastecimiento de agua dulce para hacer frente a la escasez de agua y reducir considerablemente el número de personas que sufren falta de agua (...).

Energía: 7.1, 2 y 3 (...) garantizar el acceso universal a servicios energéticos asequibles, fiables y modernos (...), aumentar considerablemente la proporción de energía renovable..., duplicar la tasa mundial de mejora de la eficiencia energética.

Crecimiento y empleo: 8.2 (...) lograr niveles más elevados de productividad económica mediante la diversificación, la modernización tecnológica y la innovación, entre otras cosas centrándose en los sectores con gran valor añadido y un uso intensivo de la mano de obra...

Infraestructuras sostenibles: 9.4 (...) modernizar la infraestructura y reconvertir las industrias para que sean sostenibles, utilizando los recursos con mayor eficacia y promoviendo la adopción de tecnologías y procesos industriales limpios y ambientalmente racionales, y logrando que todos los países tomen medidas de acuerdo con sus capacidades respectivas...

Igualdad. 10.3 Garantizar la igualdad de oportunidades y reducir la desigualdad de resultados, incluso eliminando las leyes, políticas y prácticas discriminatorias y promoviendo legislaciones, políticas y medidas adecuadas a ese respecto.

Consumo y producción sostenible: 12.5. (...) reducir considerablemente la generación de desechos mediante actividades de prevención, reducción, reciclado y reutilización., 13.1. Cambio climático: Fortalecer la resiliencia y la capacidad de adaptación a los riesgos relacionados con el clima y los desastres naturales en todos los países

Conservación y utilización de los océanos: 14. (...) prevenir y reducir significativamente la contaminación marina de todo tipo, en particular la producida por actividades realizadas en tierra, incluidos los detritos marinos y la polución por nutrientes.

Uso sostenible de los ecosistemas: 15. asegurar la conservación, el restablecimiento y el uso sostenible de los ecosistemas terrestres

18 (...) tener en cuenta las condiciones climáticas y las particularidades locales... con una metodología que puede ser diferente a escala nacional y regional $(\ldots)$ ".

19 (...) responsabilidad exclusiva de los Estados miembros establecer requisitos mínimos de eficiencia energética de los edificios y de sus elementos (...) los Estados miembros revisen periódicamente sus requisitos mínimos de eficiencia energética de los edificios (...) deben elaborar planes nacionales para aumentar el número de edificios de consumo de energía casi nulo, y deben comunicar dichos planes a la Comisión periódicamente (...) las autoridades locales y regionales son claves para que la aplicación de la presente Directiva tenga éxito, se las debe consultar y hacer partícipes" - desarrollo en artículo 20 de la Directiva-. 
respete el medio físico ( protección frente al cambio climático y el incremento de la temperatura, y protección de la biosfera y resto de especies mundiales afectadas por el crecimiento sin freno de la especie humana).

\subsection{Normativa de la Unión Europea sobre eficiencia energética}

La Unión Europea acogió favorablemente cambios en materia energética a principios de la década 2010$2020^{20}$. La doctrina advierte la urgencia de abordar la rehabilitación del parque inmobiliario en la Unión Europea (Grau Ruiz, 2017: 4). Inicialmente, la Hoja de Ruta de la Energía para 2050 -Comunicación de la Comisión Europea de 15 de diciembre de 2011- con efectos en materia de edificación -edificios de consumo de energía casi nulo-; en la misma línea, la Comunicación de la Eficiencia Energética de julio de 2014, continuó con la meta de ahorro energético del $18 \%$ o $19 \%$ en 2020, persiguiendo la disminución de costes, la reducción de la dependencia de proveedores externos de petróleo y gas, como fórmula de protección del medio ambiente. Por otra parte, el Comunicado de prensa de la Comisión Europea de 25 de septiembre de 2015 hizo alusión a la recepción de la Agenda de Desarrollo Sostenible de Naciones Unidas para 2013 con los 17 nuevos ODS y las 169 metas conexas.

La legislación de la UE, que ha incidido en la reducción del consumo energético de los edificios, es la siguiente:

- Directiva 2010/31 / UE del Parlamento Europeo y del Consejo, de 19 de mayo de 2010, sobre la eficiencia energética de los edificios (DO L 153 de 18.6.2010).

Directiva 2012/27 /UE del Parlamento Europeo y del Consejo, de 25 de octubre de 2012, sobre la eficiencia energética, que modifica las Directivas 2009/125 / CE y 2010/30 / UE y deroga las Directivas 2004/8 / CE y 2006/32 / CE (DO L 315 de 14.11.2012).

Directiva 2018/844/ UE del Parlamento Europeo y del Consejo, de 30 de mayo de 2018, modificando las anteriores.

\section{a) Directiva 2010/31 sobre eficiencia energética de los edificios}

La Directiva 2010/31 tenía como referente la Directiva 2002/91, de esquema similar, pero con un contenido mucho más escueto y reducido. La obligación de transposición de la de 2010 se limitó a las disposiciones que supusieran una modificación de fondo respecto de la Directiva 2002/91 (considerando 14), con un régimen de transposición sucesivo en función del contenido, de fechas 9 de julio de 2012, 9 de enero de 2013 y 31 de diciembre de 2015.

En los Considerandos de la Directiva 2010/31, se promueve la eficiencia energética de los edificios sobre la base de una metodología adaptada a cada caso $^{21}$, dejando en manos de los Estados miembros la responsabilidad exclusiva ${ }^{22}$ para establecer los requisitos mínimos de eficiencia energética y sus revisiones periódicas. Además, se prevé la creación de instrumentos ${ }^{23}$ de todo tipo para fomentar las medidas relativas a la eficiencia energética, en particular el certificado de eficiencia energética ${ }^{24}$ de obligado cumplimiento en las transmisiones de propiedad y las cesiones de uso (con inspección periódica y régimen de sanciones ${ }^{25}$ ).

20 Sobre la urgencia de abordar la rehabilitación del parque inmobiliario en la Unión Europea, puede consultarse Grau Ruiz, M.A. (2017) La oportunidad del estímulo fiscal a la eficiencia energética en la rehabilitación de inmuebles para lograr la sostenibilidad en la vivienda, CIRIECEspaña. Revista Jurídica, № 31, pág. 4.

21 "Se están creando o adaptando instrumentos financieros y otras medidas de la Unión con objeto de fomentar las medidas relativas a eficiencia energética (...) Al posible comprador o arrendatario de un edificio o de alguna unidad de un edificio se le debe dar, en el certificado de eficiencia energética, información correcta acerca de su eficiencia energética, así como consejos prácticos sobre cómo mejorarla (...) operaciones de inspección periódica y de mantenimiento de las instalaciones de calefacción y aire acondicionado (...) Los instaladores y constructores son claves para que la aplicación de la presente Directiva tenga éxito." -instrumentos financieros en el art. 10 de la Directiva-.

22 Artículo 11. Certificados de eficiencia energética "1. Los Estados miembros tomarán las medidas necesarias para establecer un sistema de certificación de la eficiencia energética de los edificios (...) con el fin de que los propietarios o arrendatarios del edificio o de una unidad de éste puedan comparar y evaluar su eficiencia energética." Artículo 12: Expedición de certificados de eficiencia energética "1. en edificios o unidades de estos que se construyan, vendan o alquilen a un nuevo arrendatario (...) 2. (...) se muestre al comprador o nuevo arrendatario potenciales y se entregue al comprador o nuevo arrendatario. 3. Cuando un edificio se venda o alquile antes de su construcción (...) evaluación de su eficiencia energética futura (...) indicador de eficiencia energética (...) se haga constar en los anuncios publicitarios que aparezcan en los medios de comunicación. 5. Las disposiciones del presente artículo se aplicarán de conformidad con la normativa nacional aplicable en materia de copropiedad o de comunidad de propietarios (...)".

23 Artículos 14 y 15 sobre Inspecciones; y artículo 27 acerca del Régimen sancionador.

24 Artículo 9. Edificios de consumo de energía casi nulo "1. Los Estados miembros se asegurarán de que: a) a más tardar el 31 de diciembre de 2020, todos los edificios nuevos sean edificios de consumo de energía casi nulo, y de que b) después del 31 de diciembre de 2018 , los edificios nuevos que estén ocupados y sean propiedad de autoridades públicas sean edificios de consumo de energía casi nulo.” El consumo casi nulo en viviendas nuevas se entiende como: $2020=22 \mathrm{KW} / \mathrm{h} / \mathrm{m}$; frente al actual de $75 \mathrm{KW} / \mathrm{h} / \mathrm{m}$ en viviendas nuevas y $175 \mathrm{KW} / \mathrm{h} / \mathrm{m}$ en viviendas usadas Fuente. Gas Natural. Jornadas vivienda 2015 CESINE.

25 Artículo 4 a 6: (...) Los Estados miembros tomarán las medidas necesarias para garantizar que se establezcan unos requisitos mínimos de eficiencia energética de los edificios o unidades de este con el fin de alcanzar niveles óptimos de rentabilidad (...) La Comisión establecerá (...) un marco metodológico comparativo para calcular los niveles óptimos de rentabilidad de los requisitos mínimos de eficiencia energética de los 
Con base en este marco normativo, los edificios nuevos deberán ser edificios de consumo de energía casi nulo ${ }^{26}$ el 31 de diciembre 2020 (los edificios públicos el 31 de diciembre 2018). Además, los países de la UE deben establecer requisitos mínimos ${ }^{27}$ de eficiencia energética para los edificios nuevos, y para la renovación de edificios y sustitución o modernización de los elementos de construcción de los edificios construidos (sistemas de calefacción y refrigeración, techos, paredes, etcétera).

\section{b) Directiva 2012/27 sobre eficiencia energética}

La Directiva 2012/27/UE del Parlamento Europeo y del Consejo de 25 de octubre de 2012 relativa a la eficiencia energética modifica las Directivas 2009/125/CE y 2010/30/UE, por la que se derogan las Directivas 2004/8/CE y 2006/32/CE. Esta nueva Directiva se fundamenta en las líneas de actuación ya avanzadas, incorporando a sus considerandos las medidas siguientes: independencia energética, reducción de consumo de energía, disminución de gases, impulso económico, dentro del objetivo de eficiencia energética de reducción del $20 \%$ del consumo de la misma. En particular, en el ámbito de la edificación ${ }^{28}$, se intenta orientar hacia la renovación para mejorar el rendimiento energético, fijando índices anuales de renovación, con planes de eficiencia energética sostenibles e integrados, con objetivos claros, que impliquen a los ciudadanos, y con un plan de acción sobre las adquisiciones futuras de inmovilizado por parte de las Administraciones públicas.

En el ámbito de la edificación, los artículos 4 a 6 presentan una serie de medidas de desarrollo, a corto y a largo plazo. A corto plazo, los países de la UE deben hacer renovaciones de eficiencia energética de, al menos, el 3\% de la superficie total de los edificios de propiedad y ocupadas por las Administraciones públicas al año. Además, se indica cómo hay que realizar el cálculo de este porcentaje, identificando cuáles son los edificios excluidos, por razón de su valor arquitectónico o histórico o de su finalidad de defensa nacional o de actividades religiosas. La renovación implica a todas las Administraciones públicas (Art. 5 de la Directiva 2012/27) y, a largo plazo, los estados miembros de la UE garantizarán que estas entidades adquieran a futuro sólo productos, servicios y edificaciones que tengan un alto rendimiento energético (art. 6 de la Directiva 2012/27) ${ }^{29}$. Además, deberán elaborar estrategias nacionales de rehabilitación de edificios, a

edificios y de sus elementos (...) edificios nuevos cumplan los requisitos mínimos de eficiencia energética establecidos (...) cuando se efectúen reformas importantes en edificios, se mejore la eficiencia energética del edificio o de la parte renovada (...) siempre que ello sea técnica, funcional y económicamente viable.".

26 “(...) los Estados miembros deberían crear una estrategia a largo plazo para después de 2020 destinada a movilizar inversiones en la renovación de edificios residenciales y comerciales para mejorar el rendimiento energético del parque inmobiliario (...) El ritmo de renovación de edificios tiene que aumentar ya que el parque inmobiliario existente constituye el sector con mayor potencial de ahorro de energía (...) Los edificios de propiedad estatal... conviene fijar un índice anual de renovación de edificios que las Administraciones centrales tengan en propiedad y ocupen con objeto de mejorar su rendimiento energético. Este índice de renovación se entiende sin perjuicio de las obligaciones relativas a los edificios de consumo de energía casi nulo establecidas en la Directiva 2010/31/UE (...) La obligación de renovar la superficie útil de los edificios de la Administración central debería aplicarse a los órganos administrativos cuya competencia se extienda a la totalidad del territorio de un Estado miembro (...) Algunos municipios y otros organismos públicos de los Estados miembros ya han puesto en práctica planteamientos integrados sobre ahorro de energía y abastecimiento de energía... Debe fomentarse el intercambio de experiencias entre municipios y otros organismos públicos acerca de las experiencias más innovadoras. (...) Administraciones centrales que firmen contratos de obras, suministros o servicios deben dar ejemplo y tomar decisiones de compra eficientes en cuanto a la energía (...)".

27 Artículos 5 y 6: "Función ejemplarizante de los edificios de los organismos públicos 1 . Sin perjuicio de lo dispuesto en el artículo 7 de la Directiva 2010/31/UE, cada uno de los Estados miembros se asegurará de que, a partir del 1 de enero de 2014 , el $3 \%$ de la superficie total de los edificios con calefacción y/o sistema de refrigeración que tenga en propiedad y ocupe su Administración central se renueve cada año (...) 1. Los Estados miembros garantizarán que las Administraciones centrales adquieran solamente productos, servicios y edificios que tengan un alto rendimiento energético, en la medida en que ello sea coherente con la rentabilidad, la viabilidad económica, la sostenibilidad en un sentido más amplio, la idoneidad técnica (...)".

28 Artículo 4: "Renovación de edificios. Los Estados miembros establecerán una estrategia a largo plazo para movilizar inversiones en la renovación del parque nacional de edificios residenciales y comerciales, tanto público como privado (...) A más tardar el 30 de abril de 2014 , se publicará una primera versión de la estrategia, que se actualizará cada tres años y será remitida a la Comisión en el marco de los Planes nacionales de acción para la eficiencia energética.".

29 Cada vez reviste mayor importancia para la Unión Europea la reducción del consumo y despilfarro de energía. Los líderes de la Unión establecieron en 2007 el objetivo de reducir, a más tardar en 2020, el consumo anual de energía de la Unión en un 20 \%. Las medidas de eficiencia energética se consideran cada vez más un medio no solo para conseguir un abastecimiento de energía sostenible, reducir las emisiones de gases de efecto invernadero, mejorar la seguridad del suministro y rebajar los gastos de importación, sino también para fomentar la competitividad de la Unión. Es por todo ello que la eficiencia energética representa una de las prioridades estratégicas de la Unión de la Energía y que la Unión fomenta el principio de «anteponer la eficiencia energética». El futuro marco de actuación para el periodo posterior a 2030 está en proceso de debate. http://www.europarl.europa.eu/factsheets/es/sheet/69/la-eficiencia-energetica.

Objetivos de la modificación de la Directiva en 2018: reducción del consumo energético tanto en edificios nuevos como ya existentes; puestos de carga para vehículos eléctricos en los edificios nuevos; estrategias nacionales de renovación e indicadores para evaluar la eficiencia

Máxima eficiencia energética en los inmuebles de la UE para 2050 y, para ello, apuestan por la renovación de los edificios para reducir su consumo.

La nueva legislación obliga a los estados miembros a desarrollar estrategias nacionales a largo plazo para la renovación de edificios tanto públicos como privados, con el objetivo de recortar su volumen de emisiones contaminantes entre un $80 \%$ y $85 \%$ en relación al nivel de 1990 . El texto salió adelante con 546 votos favorables, 35 en contra y 96 abstenciones.

Los planes nacionales para un parque inmobiliario "descarbonizado" en 2050 deberán incluir objetivos orientativos para 2030 y 2040. Harán falta indicadores de progreso cuantificable para verificar el cumplimiento de las estrategias nacionales.

La directiva introduce disposiciones para fomentar la movilidad eléctrica en los edificios nuevos y lo que son objeto de renovación, como la ubicación de al menos un punto de recarga en inmuebles con más de diez plazas de aparcamiento y la instalación de cableado para la recarga. 
nivel nacional, que pueden incluir en sus planes de acción de eficiencia energética (art. 4 de la Directiva 2012/27).

\section{c) Directiva 2018/844 UE de 30 de mayo}

Como ya se ha enunciado con anterioridad, en el marco de los Objetivos de Desarrollo Sostenible de la Agenda 2030, el Objetivo número 11 sobre Ciudades y Comunidades Sostenibles supuso la aprobación de la Directiva 2018/844 UE de 30 de mayo, modificando las anteriores (Directivas 2010/31 de eficiencia energética de edificios y 2012/27 de eficiencia energética) para lograr "un parque inmobiliario descarbonizado y altamente eficiente (...) para transformar los edificios existentes en edificios de consumo de energía casi nulo (...) con una renovación a una tasa media anual del 3\% (...) aplicando las Directrices de la OMS sobre la calidad de aire interior (...) y apoyando medidas de fomento de financiación inteligente para edificios inteligentes de la Comisión Europea".

Esta Directiva anuncia una mejora de la transparencia de los certificados de eficiencia energética, garantizando el establecimiento y la aplicación uniformes de todos los parámetros de cálculo necesarios, tanto por lo que respecta a la certificación como a los requisitos mínimos de eficiencia energética, y propone un sistema de control posterior automatizado y electrónico.

Así pues, con la modificación de la Directiva en 2018, la implantación de sistemas de certificación que acrediten la construcción y la rehabilitación sostenible se sigue configurando como la herramienta más potente para impulsar el futuro del sector (Rua y López Mesa, 2012: 307) ${ }^{30}$. No obstante, en la práctica, la certificación sigue resultando poco atractiva económicamente, por lo que suelen coexistir determinados problemas sociales, económicos y administrativos para su implantación, así como múltiples diferencias de percepción entre los distintos grupos de interés. Por estos motivos el apoyo público para su promoción resulta imprescindible. Además, como se demostrará en este artículo, las medidas fiscales pueden configurarse como uno de los instrumentos más poderosos para la extensión de la certificación en España.

La Directiva será revisada (a más tardar) el 1 de enero de 2026 por la Comisión (siendo asistida por el Comité establecido en el artículo 26), que presentará propuestas a la luz de la experiencia adquirida y de los progresos realizados durante su aplicación. Además, esta Comisión será el órgano competente para evaluar (artículo 19), en particular, la necesidad de seguir mejorando los certificados de eficiencia energética.

\section{Hipótesis y metodología}

La hipótesis principal que se pretende verificar con la investigación es que la sostenibilidad en el sector de la edificación se encuentra todavía en una etapa incipiente, ya que existen pocos incentivos que contribuyan a garantizar su buen desarrollo en España (Borgia, 2017: 46; Castellano, 2015: 32) 31. Además, la mayor parte

También está prevista la creación de una herramienta, denominada "indicador de inteligencia”, para medir la capacidad de los edificios para mejorar su funcionamiento y su interacción con el sistema en función de las necesidades de sus ocupantes, reduciendo así el uso de energía. La Comisión Europea deberá desarrollar esta idea antes del final de 2019.

Los edificios nuevos, y los renovados en los que se sustituyan los sistemas de calefacción, deberán contar con dispositivos automáticos para regular la temperatura. Se endurecen también las normas sobre inspección de los sistemas de calefacción y refrigeración. En la declaración del ponente, Bendt Bendtsen (PPE, Dinamarca) se puso de manifiesto que la revisión de esta directiva era una señal clara del compromiso con los objetivos internacionales de lucha contra el cambio climático y de la determinación de avanzar hacia la Unión Energética, cuando destacó lo siguiente: "El sector de la construcción juega un papel clave. Ofrecemos certidumbre a los inversores de que la renovación de edificios es un área prioritaria".

http://www.europarl.europa.eu/news/es/press-room/20180411IPR01516/ahorro-energetico-eficiencia-maxima-en-los-edificios-de-la-ue-para$\underline{2050 .}$.

30 Rua, M. J., López Mesa, B. (2012) Certificación energética de edificios en España y sus implicaciones Económicas. Informes de la Construcción, Vol. 64, No 527 , pág. 307.

31 Han sido medidas clásicas en nuestro Ordenamiento, siempre que se cumplan los requisitos legales, la deducción fiscal por obras de rehabilitación en el IRPF, y el tipo de IVA reducido aplicable a quienes realicen obras de rehabilitación y obras de renovación y reparación de edificios o partes de los mismos destinados a viviendas.

Otra cuestión, menos tratada, que indirectamente afecta también a la sostenibilidad de la vivienda es el mantenimiento de viviendas vacías. Aunque se haya reconocido por el Tribunal Constitucional la posibilidad de la aplicación de gravámenes o recargos sobre las mismas, quizás debería promoverse igualmente la parte tocante a su rehabilitación, cuando ésta sea una de las causas de su falta de ocupación. Sobre la constitucionalidad de la citada utilización del sistema tributario con fines disuasorios o sancionadores: "Un supuesto paradigmático de utilización extrafiscal del tributo (...) es el relacionado con el aseguramiento de la función social del derecho de propiedad (art. 33.2 CE), habiendo llegado el legislador a alumbrar impuestos específicamente diseñados con el fin primordial de penalizar la infrautilización de determinados tipos de inmuebles por parte de sus titulares (...) los ejemplos más recientes relacionados con la promoción del derecho a una vivienda digna a través de la aplicación de gravámenes o recargos sobre viviendas vacías. Las dudas de constitucionalidad ya han sido despejadas también por el TC en relación con el recargo que, a imagen y semejanza del previsto, pero nunca activado por estar pendiente de desarrollo reglamentario, en el artículo 72.4 del TRLRHL, se establece en el art. 14.5 de la Norma Foral 12/1989, de 5 de julio, del impuesto de bienes inmuebles de Guipúzcoa. Así, los Autos del TC 109/2017, 110/2017 y 111/2017, todos ellos de 18 de julio de 2017, rechazan por manifiestamente infundadas las cuestiones prejudiciales elevadas sobre dicha norma, declarando su compatibilidad tanto con los principios de reserva de Ley tributaria y de seguridad jurídica, como con el principio de capacidad económica y de igualdad tributaria" (Aguacil et al., 2019: 86). 
de ellos se encuentran dispersos y varían en función de la normativa local ${ }^{32}$ y autonómica. En este sentido, la tabla 1 recoge la variada regulación existente (sin entrar en el detalle de los requisitos exigibles y las cuantías de los beneficios otorgados que adolecen de falta de homogeneidad) en el marco del IRPF.

Tabla. 1. Deducciones relativas a la sostenibilidad de la vivienda adoptadas por las Comunidades Autónomas en el IRPF en 2018

\begin{tabular}{|c|c|}
\hline CC.AA. & Deducción autonómica en el IRPF \\
\hline Aragón & Por adquisición o rehabilitación de vivienda habitual en núcleos rurales o análogos \\
\hline Illes Baleares & Por determinadas inversiones de mejora de la sostenibilidad de la vivienda habitual \\
\hline Canarias & Por obras de rehabilitación energética y reforma de la vivienda habitual \\
\hline Cantabria & Por obras de mejora en viviendas \\
\hline Castilla y León & $\begin{array}{l}\text { Por inversión en instalaciones medioambientales y de adaptación a personas con } \\
\text { discapacidad en vivienda habitual } \\
\text { Por inversión en rehabilitación de viviendas destinadas a alquiler en núcleos rurales }\end{array}$ \\
\hline Cataluña & Rehabilitación de la vivienda habitual \\
\hline Extremadura & $\begin{array}{l}\text { Por adquisición o rehabilitación de vivienda habitual para jóvenes y para víctimas } \\
\text { del terrorismo }\end{array}$ \\
\hline Galicia & $\begin{array}{l}\text { Por inversión en instalaciones de climatización y/o agua caliente en la vivienda } \\
\text { habitual, que empleen energías renovables } 10 \% \text { destinadas exclusivamente al } \\
\text { autoconsumo }\end{array}$ \\
\hline Región de Murcia & Por instalaciones de recursos energéticos renovables en viviendas \\
\hline La Rioja & $\begin{array}{l}\text { Por adquisición o rehabilitación de segunda vivienda en el medio rural } \\
\text { Por rehabilitación de vivienda habitual } \\
\text { Por adquisición, construcción o rehabilitación de vivienda habitual en pequeños } \\
\text { municipios }\end{array}$ \\
\hline $\begin{array}{l}\text { Comunidad } \\
\text { Valenciana }\end{array}$ & $\begin{array}{l}\text { Por adquisición/rehabilitación vivienda habitual con ayudas públicas } \\
\text { Por obras de conservación o mejora de la calidad, sostenibilidad y accesibilidad en } \\
\text { la vivienda habitual efectuadas en } 2014 \text { y } 2015 \\
\text { Por obras de conservación o mejora de la calidad, sostenibilidad y accesibilidad en } \\
\text { la vivienda habitual efectuadas en el periodo } \\
\text { Por instalaciones de autoconsumo de energía eléctrica o para aprovechamiento de } \\
\text { fuentes de energía renovable en la vivienda habitual o edificio donde se ubique }\end{array}$ \\
\hline
\end{tabular}

Fuente: Agencia Estatal de Administración Tributaria. Manual práctico de renta 2018

32 "Otra alternativa a tomar en consideración para incentivar las actuaciones rehabilitadoras en edificios es el establecimiento de bonificaciones o incluso exenciones en el pago de alguno de los impuestos municipales cuyo hecho imponible esté relacionado con la ejecución de obras o con el valor de los inmuebles (Impuesto sobre Construcciones y Obras -ICIO- o incluso, Impuesto sobre Bienes Inmuebles -IBI-).

Lo mismo cabe decir respecto de la posibilidad de introducir exenciones o bonificaciones en el importe de alguna tasa municipal vinculada con la propia actividad edificatoria (tasas devengadas como consecuencia de la emisión de la licencia de obras o de la declaración responsable, en su caso)". FEMP, FUNDACIÓN CASA QUE AHORRA: Documento de recomendaciones sobre incentivos a la rehabilitación con criterios de eficiencia energética desde una perspectiva municipal. Disponible en http://femp.femp.es/files/3580-1587fichero/Documento incentivos rehabilitacion.pdf [última consulta 24 de noviembre de 2019]. 
Por otra parte, en materia de Cooperativas de viviendas, la Ley de Régimen Fiscal de Cooperativas, de 1990, no contempla un impulso real y actual de las cooperativas, por lo que la doctrina ${ }^{33}$ ha invitado reiteradamente a su reforma (Martínez, Ibáñez y Pozuelo, 2015: 134; Romero y Marí, 2015: 24).

Por tanto, en función de lo señalado, es conveniente emprender medidas de mejora que permitan reforzar la rehabilitación y la sostenibilidad de las viviendas en nuestro país. Además de una necesaria unificación normativa que contribuya a generar un marco estable (Gadea, Aixabal e Izquierdo, 2014: 104).

Para intentar constatar la hipótesis general de investigación, se ha generado un marco analítico integrado por cinco dimensiones: sostenibilidad en el sector; certificación y eco-etiquetas; recursos económicos y financieros (ayudas y subvenciones); normativa aplicada; y comunicación con agentes del sector y la sociedad. Como se puede apreciar en la tabla 2, en cada dimensión se ha intentado medir y evaluar la sostenibilidad en el sector de la edificación mediante la aplicación de una serie de variables que permitan conocer cuál es el estado de la cuestión (diagnóstico de situación), así como cuáles son las posibles medidas de mejora al respecto.

Tabla. 2. Marco analítico para evaluar la sostenibilidad en el sector de la edificación

\begin{tabular}{|c|c|}
\hline Dimensiones & Variables \\
\hline Sostenibilidad en el sector & $\begin{array}{ll}\text { - } & \text { Ámbito de actividad del sector edificación con más acciones } \\
\text { - } & \text { Coste añadido de la sostenibilidad } \\
\text { - } & \text { Barreras en el desarrollo de la sostenibilidad } \\
\text { - } & \text { Propuestas de mejora en materia de sostenibilidad }\end{array}$ \\
\hline $\begin{array}{l}\text { Certificación } \\
\text { etiquetas }\end{array}$ & $\begin{array}{cl}\text { - } & \text { Nivel de conocimiento de las herramientas de certificación por } \\
\text { parte de los grupos de interés } \\
- & \text { Certificaciones con un mayor grado de aplicación } \\
- & \text { Herramientas adicionales utilizadas (que no sean de certificación) } \\
\text {-CDC, } & \text { RSE, etc.-. } \\
\text { - } & \text { Barreras en el desarrollo de la certificación } \\
\text { - } & \text { Beneficios o ventajas de la certificación } \\
\text { - } & \text { Impacto de la certificación sobre la rentabilidad } \\
\text { - } & \text { Impacto de la certificación sobre la imagen del sector }\end{array}$ \\
\hline $\begin{array}{ll}\text { Recursos económicos } & y \\
\text { financieros (ayudas } & y \\
\text { subvenciones) } & \end{array}$ & $\begin{array}{l}\text { - } \quad \text { Ayudas y subvenciones aplicadas o solicitadas y ámbito de } \\
\text { procedencia de las mismas } \\
\text { - } \quad \text { Motivos por los que no se reciben o aplican ayudas } \\
\text { - } \quad \text { Medidas fiscales prioritarias para mejorar la sostenibilidad: - } \\
\text { incentivos fiscales, suplemento en el IBI, Pasaporte electrónico } \\
\text { - } \quad \text { Propuestas de mejora en materia de financiación } \\
\text { - }\end{array}$ \\
\hline Normativa aplicada & 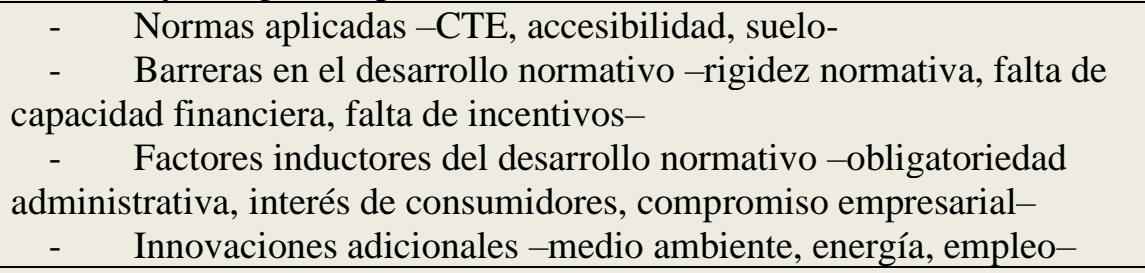 \\
\hline $\begin{array}{ll}\text { Comunicación } & \text { con } \\
\text { agentes del sector y la } \\
\text { sociedad }\end{array}$ & $\begin{array}{l}\text { - Nivel de interacción de los grupos de interés con otros agentes - } \\
\text { desarrollo de proyecto- } \\
\text { - } \quad \text { Escasez de campañas de información y sensibilización en materia } \\
\text { de sostenibilidad en el sector de la edificación }\end{array}$ \\
\hline
\end{tabular}

Fuente: Elaboración propia.

Martínez, Ibañez y Pozuelo (2015) La presión fiscal en las cooperativas: una valoración por tamaños, comunidades y sectores para el período 2008-2011. REVESCO. Revista de Estudios Cooperativos, № 119, pág. 134, señalan que "las cooperativas tienen sus normas fiscales específicas aprobadas por la Ley 20/1990 (Régimen fiscal de cooperativas - RFC en adelante), aunque deben aplicar el régimen general (Texto Refundido de la Ley del Impuesto sobre Sociedades en el período objeto de estudio y Ley 27/2014 del Impuesto sobre Sociedades en la actualidad) en las cuestiones que no estén expresamente previstas en aquellas. Según el RFC cabe distinguir entre cooperativas protegidas y especialmente protegidas. En estas últimas se observa un mejor trato fiscal al querer incentivar la modernización y desarrollo de sectores económicos como la agricultura, la ganadería y la pesca". Y Romero y Marí (2015) Algunos aspectos críticos en la aplicación del impuesto de sociedades a las cooperativas según el régimen fiscal de cooperativas. La necesidad de su reforma. REVESCO. Revista de Estudios Cooperativos, No 118 , pág. 24 , que "con todo lo descrito, hemos pretendido demostrar la obsolescencia de la Ley 20/90 en lo que concierne al IS, al menos parcialmente , y denunciar las complicaciones contables y fiscales que la existencia de dos bases y dos tipos tienen para las cooperativas, algo inaudito en la legislación cooperativa europea. Ningún país significativo de nuestro entorno tiene para sus cooperativas dos bases imponibles ni dos tipos de gravamen: ni Francia, Italia, Alemania, Inglaterra, etc., ni tampoco aquellos con gran tradición cooperativa: Dinamarca, Holanda, Austria, etc. “. 
Los datos de la investigación se han recopilado mediante la utilización de una técnica de investigación cuantitativa: la encuesta. En concreto, se diseñó una encuesta, inicialmente compuesta por 60 preguntas (posteriormente reducidas a 15), que se realizaron desde comienzos de 2017 hasta finales de 2018. Los destinatarios de la misma fueron los grupos de interés en el sector de la edificación y la rehabilitación, debido a su constatada experiencia con el manejo de las certificaciones, así como por su impacto real en la sostenibilidad. En la encuesta participaron 23 grupos de interés pertenecientes al sector público (principalmente ayuntamientos con un índice de participación del 17,6\%) y al sector privado (arquitectos del sector de cooperativas de viviendas, empresas promotoras, empresas de arquitectura, consultorías, Colegio oficial de arquitectos de Madrid, Colegio oficial de arquitectos técnicos de Madrid, Escuela de arquitectura de la UPM, Escuela de edificación de la UPM, entre otros).

\section{Resultados}

\subsection{Foco de la sostenibilidad en el sector de la edificación}

En el sector de la edificación sostenible, el ámbito en el que se identifica un mayor número de acciones ha sido el de los edificios (40\%). Como se puede observar en la figura 1, los grupos de interés también destacan otros ámbitos, aunque en menor medida: el diseño sostenible (15\%), las energías renovables (15\%), los sistemas urbanos e infraestructuras $(15 \%)$ y los materiales y productos $(10 \%)$.

Figura. 1. Ámbito de actividad en que se ha actuado para lograr una edificación sostenible

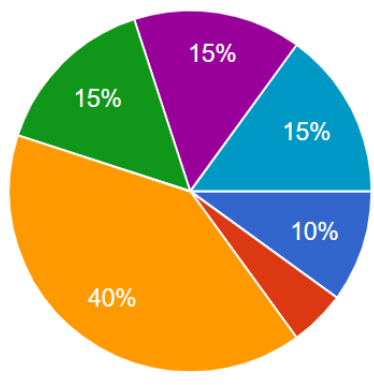

Materiales y productos

Sistemas constructivos

Edificios

Sistemas urbanos e infraestructuras

Diseño sostenible

Energías renovables

Debe añadirse que una parte de los grupos de interés $(55,6 \%)$ resalta que la sostenibilidad supone un coste añadido para la actividad, mientras otros consideran que no lo es (44,4\%). Los que opinan que es un coste, en particular, indican que este coste viene provocado por los sobrecostes; la necesidad de utilizar materiales eficientes (que pueden repercutir en el coste); la puesta al día en las nuevas normativas sectoriales; los controles; la necesidad de mayor planificación; la utilización de tecnología; y el aumento de la dedicación que no se traduce en un reconocimiento; entre otros motivos.

Por otra parte, se han identificado una serie de barreras o dificultades que ralentizan el desarrollo de la sostenibilidad en el sector de la edificación, como muestra la figura 2. En concreto, un 26,6\% de los encuestados destaca la falta de apoyo (líneas de subvención o ayudas), un 21,1\% el déficit de recursos, un $15,8 \%$ la falta de demanda, un 15,8\% la falta de obligación, un 10,5\% la falta de fiabilidad y eficacia, y un $10,5 \%$, la falta de regulación (véase figura 2). 
Figura. 2. Barreras para el desarrollo de la sostenibilidad

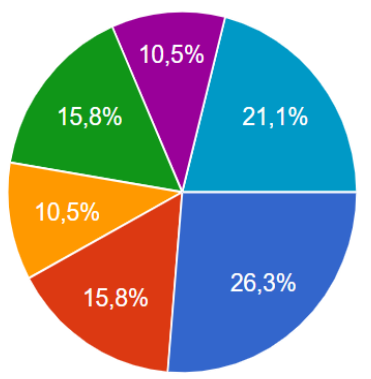

Falta de apoyo: líneas de subvención, ayudas...

Falta de demanda

Falta de fiabilidad y eficacia de las soluciones

Falta de obligación

Falta de regulación

Falta de recursos

Para mejorar la sostenibilidad en el sector de la edificación, los grupos de interés resaltan distintas iniciativas, que podrían agruparse en varias categorías: estratégicas; normativas; económicas y financieras; e informativas y formativas.

En relación con las acciones estratégicas se destaca el fomento de políticas nacionales y municipales que apuesten por la construcción sostenible, empezando por dar ejemplo en los edificios públicos, para que la sociedad perciba beneficios de integrar la sostenibilidad en el entorno construido y, así, generar un aumento de la demanda, premiando incluso las buenas prácticas con apoyo financiero para incentivar el desarrollo de estas iniciativas.

En cuanto a las recomendaciones normativas señalan que deben ofrecerse facilidades para que el sector pueda ajustarse al cumplimiento de la normativa, que requiere principios de diseño sostenible en la edificación (lo que supone un coste adicional nulo).

Respecto a los aspectos económicos, se propone aumentar las subvenciones y las ayudas para mejorar las posibilidades de financiación de proyectos de construcción sostenible.

Por último, en materia de información y formación, los encuestados señalan que se debe formar en desarrollo sostenible, tanto a los técnicos, como a los futuros profesionales, incluyendo asignaturas en los planes de estudios de aquellas carreras relacionadas con la construcción y el planeamiento urbano. Además, hay que informar y sensibilizar a los grupos de interés (a los promotores, en especial) y a la sociedad, en general, sobre las ventajas y la importancia medioambiental de la construcción sostenible.

\subsection{Certificación y eco-etiquetas}

Como se puede observar en la figura 3, los resultados de la encuesta ponen de manifiesto que el $73.7 \%$ de los grupos de interés conoce las distintas herramientas de certificación sostenible de edificios. En concreto, las que más se suelen utilizar son: PASSIVEHAUSE $(38,5 \%)$, LEED $(23,1 \%)$ y VERDE $(23,1 \%)$, y en un porcentaje bajo, del 7,7\% SPATIUM.

Figura. 3. Conocimiento de las herramientas de certificación sostenible

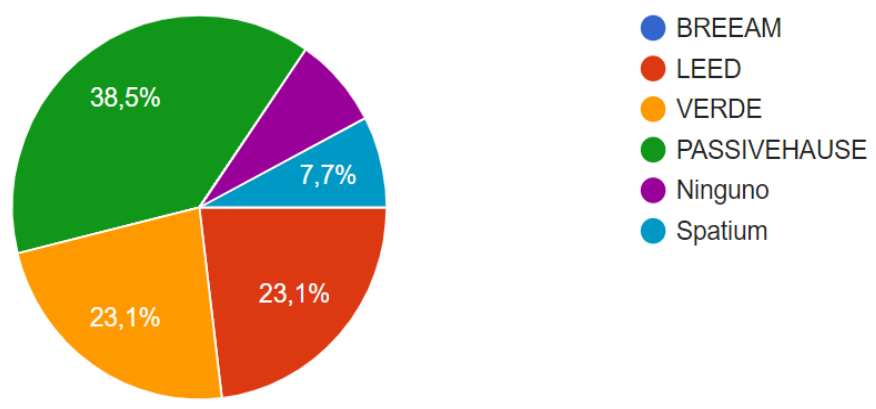

Además, puede verse en la figura 4 que los grupos interés señalan que también suelen emplear otros medios para obtener información sobre el impacto social de su actividad, mayoritariamente los estándares o los protocolos de buenas prácticas $(70,6 \%)$, y minoritariamente las evaluaciones de sostenibilidad voluntarias $(23,5 \%)$ o los informes de responsabilidad social empresarial - RSE- $(6 \%)$. 
Figura. 4. Otros medios de información

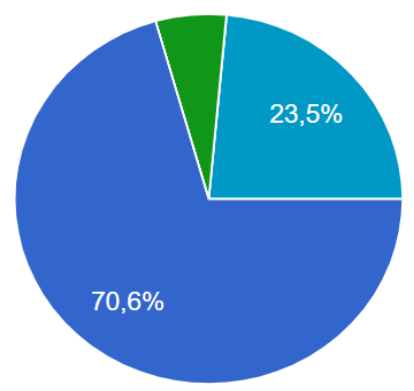

Estándares o protocolos de buenas prácticas en la edificación

Herramientas de diseño y análisis del ciclo de vida (software) -ACV, ETIQUETAS ECOLÓGICAS-

Memorias

Informes de responsabilidad socia

Informes de rendición de cuentas

Evaluaciones de sostenibilidad voluntaria

Los resultados de la investigación evidencian que las principales barreras que impiden el desarrollo de la certificación son ajenas a la construcción en sí misma y que paradójicamente se vinculan a los aspectos de gestión, los cuales tienen una influencia decisiva por delante de cuestiones ambientales y de mejora social, como indica la figura 5. En concreto, un $27,8 \%$ de los encuestados destaca que las principales dificultades se encuentran en el procedimiento de gestión de la certificación, un 22,2\% en la falta de demanda de productos certificados y un $11,1 \%$ en la excesiva burocracia.

Figura. 5. Barreras al desarrollo de la certificación

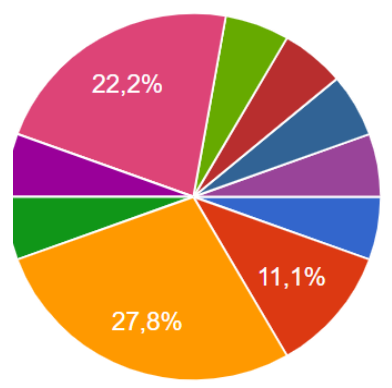

Costes

Burocracia

Dificultades ligadas a los cambios e...

Existencia de muchas ecoetiquetas

Disputas entre distintos sistemas d...

Falta de información

Falta de demanda de productos cer...

Falta de apoyo o incentivo por parte...

$1 / 2 \nabla$

En relación con los beneficios que puede aportar la certificación, se observa en la figura 6, que la mayor parte de los participantes $(83,3 \%)$ consideran que las certificaciones contribuyen a mejorar la imagen del sector y que también aumenta la rentabilidad (72,2\%). Si se indaga en la correlación entre la rentabilidad y la certificación, una parte de los grupos de interés $(11,1 \%)$ pone de manifiesto que la rentabilidad también puede disminuir "al no poder trasladar el coste de la certificación" y otra parte de los encuestados destaca que la certificación no influye en la rentabilidad.

Figura. 6. Impacto de las certificaciones sobre la rentabilidad

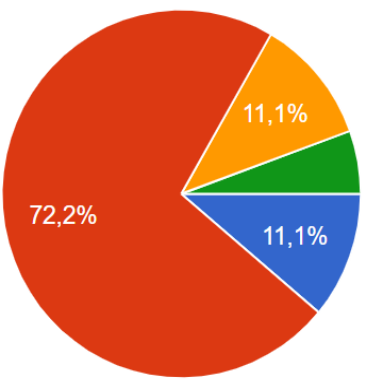

Disminuye, al no poder trasladar el coste de la certificación

Aumenta, al poder aumentar el precio más que los costes de la certificación

No influye

No influye en la rentabilidad, al poder aumentar el precio de la certificación sólo en la medida necesaria para cubrir los costes de la certificación 


\subsection{Recursos económicos y financieros para desarrollar la sostenibilidad en el sector de la edificación}

Respecto a los recursos económicos utilizados para desarrollar la sostenibilidad en la edificación, un 47,4 \% de los encuestados admite haber aplicado algún tipo de ayuda frente al 52,6\% que no lo ha hecho.

En la figura 7 se puede identificar cómo estas ayudas son principalmente municipales $(77,8 \%)$ y que sólo una minoría de participantes en la encuesta recurre a las del Plan Estatal $(22,2 \%)^{34}$.

Figura. 7. Ayudas solicitadas

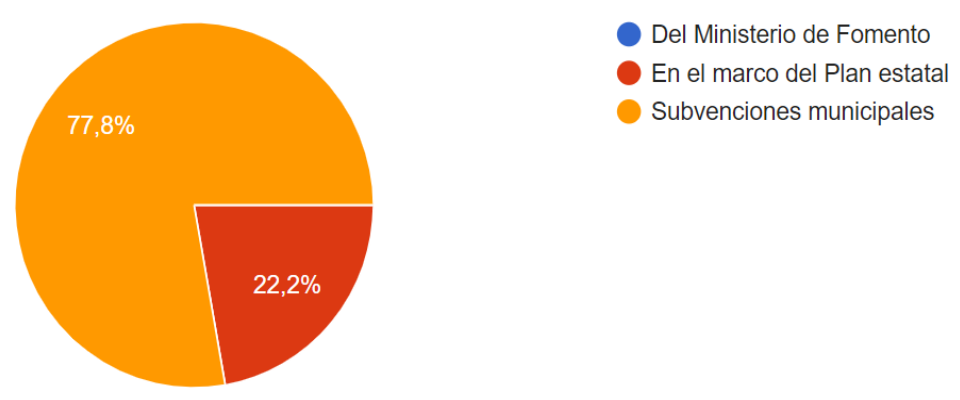

La figura 8 muestra los principales motivos de los grupos de interés para no recibir o aplicar ayudas son los siguientes: el déficit de medios económicos, técnicos y humanos $(27,8 \%)$; la confusión en las líneas de financiación, ayudas y subvenciones que se pueden solicitar (22,2\%); y los problemas de compatibilidad en los plazos existentes para solicitar ayudas nacionales, regionales y locales (22,2\%). Por tanto, los procedimientos de gestión y los recursos se destacan como dos aspectos clave que inciden en el desarrollo de la sostenibilidad en el sector.

Figura. 8. Razones por las que no se pueden aplicar las ayudas.

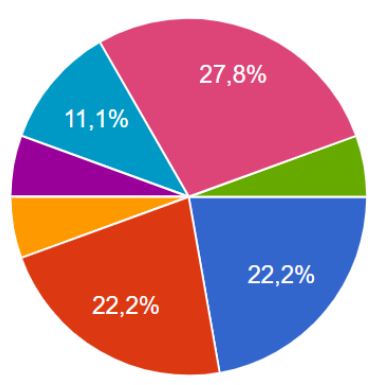

Confusión entre ayudas -

subvenciones-y líneas de financia..

Problemas de compatibilidad de los plazos de presentación de solicitud..

- La concurrencia competitiva para p...

Déficit en la garantía técnica del pro..

Falta de una línea y seguro de cauc..

Falta de un consorcio económico e...

Déficit de medios económicos, técni...

¿Afecta al ámbito público?

En relación con las medidas fiscales que los grupos de interés aplicarían para mejorar la situación en materia de sostenibilidad, puede verse en la figura 9 que un 57,9\% señala que debería incrementarse la ayuda del 35\% al 50\% en las actuaciones de rehabilitación en materia de accesibilidad en edificios y espacios públicos; un 31,6\% destaca que habría que reducir el IVA del $21 \%$ al $10 \%$ ó al $4 \%$, o incluso otorgar una exención -concretamente según la escala de la actuación: edificio (10\%), barrio (4\%), área (exención)-; y un $10,5 \%$ señala la exención de declaración de las subvenciones en el IRPF. Sin embargo, no queda claro qué medidas se estiman más adecuadas para aumentar y mejorar la certificación: la bajada del IVA, las deducciones de gastos en el IRPF o Impuesto sobre Sociedades, y/o los incentivos para la compra pública y subvenciones.

34 Real Decreto 106/2018, de 9 de marzo, por el que se regula el Plan Estatal de vivienda 2018-2021, modificado por Real Decreto-Ley 21/2018, de 14 de diciembre, de "medidas urgentes en materia de vivienda y alquiler. Sobre la evolución de las políticas públicas en España puede consultarse Bueno Maluenda, M.C. (2017) "Repensar la política fiscal sobre la rehabilitación de viviendas: propuesta de régimen fiscal para iniciativas cohousing”, CIRIEC-España. Revista Jurídica, № 31, pág. 4 y ss. 
Figura. 9. Medidas fiscales prioritarias para mejorar la sostenibilidad

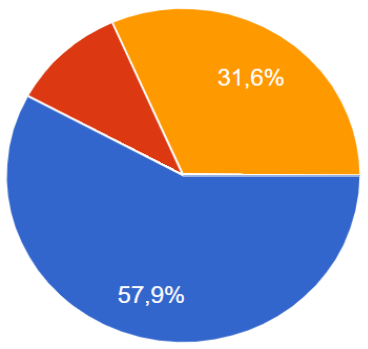

Incrementar la ayuda del $35 \%$ al $50 \%$ en las actuaciones de rehabilitación en materia de accesibilidad en edificios y espacios públicos

Exención de declaración de las subvenciones en el IRPF

Reducción del IVA del $21 \%$ al $10 \%$ ó $4 \%$, o exención: escala edificio $(10 \%)$ barrio (4\%), área (exención)

Inversión del sujeto pasivo en el IVA

Por otra parte, con respecto a la valoración de algunas posibles mejoras en materia financiera: un 94,7\% de los encuestados considera que sería interesante fomentar ayudas al estudio de la eficiencia energética de los edificios a través de un gestor técnico-financiero de rehabilitación.

Un porcentaje mayoritario $(94,7 \%)$ se muestra favorable en condicionar los incentivos fiscales al cumplimiento de los protocolos de certificaciones medioambientales. Cabe señalar que, durante el debate interinstitucional para la actualización de la Directiva de Eficiencia Energética de los Edificios, que forma parte del paquete "Energía limpia para todos los europeos", se reforzó la regulación de los certificados, facilitando el uso de sus versiones digitales y bases de datos para mejorar el seguimiento.

Un 68,4\% estaría dispuesto a pagar el coste de la rehabilitación en un plazo de varios años -a través de un suplemento en el IBI- (teniendo en cuenta que el incumplimiento del pago podría considerarse de carácter tributario).

Un 89,5\%, aceptaría cambiar el certificado por un pasaporte electrónico en el que constasen las sucesivas renovaciones del edificio, y en el que hubiese permisos de acceso diferentes según el tipo de usuario, teniendo en cuenta que las autoridades tributarias podrían consultarlo para la concesión de incentivos fiscales. Este Pasaporte de Renovación de Edificios se define como un documento -en formato electrónico -o en papel- en el que se esboza una hoja de ruta de renovación a largo plazo (hasta 15 o 20 años), paso a paso, para un edificio específico, como resultado de una auditoría energética in situ que cumple con los criterios e indicadores de calidad específicos establecidos durante la fase de diseño y en diálogo con los propietarios del edificio. Esto puede combinarse con un repositorio de información relacionada con el edificio (diario) sobre aspectos tales como el consumo y la producción de energía, el mantenimiento ejecutado y los planos del edificio. El cuaderno de bitácora también podría incluir otra información relacionada con cada edificio, como las opciones de financiación disponibles en la zona para los proyectos de renovación (por ejemplo, préstamos ecológicos o créditos fiscales), y los propietarios podrían facilitar información a las autoridades públicas (por ejemplo, al municipio o a la oficina del impuesto sobre bienes inmuebles) ${ }^{35}$.

Además, existe la opción de adoptar algunas medidas temporales para dinamizar las actuaciones de rehabilitación y mejora energética. Recientemente se ha experimentado en el Derecho comparado, por ejemplo, en Italia. En este país, el Decreto ley No. 30, de 30 de abril de 2019 (publicado ese mismo día en el Boletín Oficial) ha introducido una serie de incentivos para fomentar el "re-desarrollo" del sector inmobiliario. Fundamentalmente suponen adoptar una medida de simplificación, que suaviza la presión fiscal para agilizar la inversión y el tráfico en el sector inmobiliario. Así, el gravamen por el registro, las hipotecas y el catastral se aplican a tanto alzado (a razón de 200 euros por cada uno de ellos, en lugar de aplicar los impuestos proporcionales). El supuesto de hecho es que una empresa compre edificios entre el 1 de mayo de 2019 (fecha de entrada en vigor del Decreto -aunque habrá de convertirse en ley, probablemente con alguna modificación a los 60 días-) y el 31 de diciembre de 2021 para demolerlos, desarrollarlos mejorando sus características de eficiencia energética o antisísmicas y los venda en los 10 años siguientes. Si no cumple estos requisitos se aplicarán los impuestos a la transmisión -conforme a las reglas ordinarias- más un 30\% de penalización e interés de demora.

El 9 de octubre de 2019 la Comisión de Infraestructuras y Urbanismo del Departamento de Asuntos Regulatorios y Europeos de la CEOE ha hecho público el Informe sobre la Vivienda en España: propuestas de mejora $^{36}$ con la finalidad de que el nuevo gobierno las tome en consideración en su política de vivienda, ocupando una "verdadera dimensión de Estado".

35 Se trata del "individueller Sanierungsfahrplan" en Alemania, "Woningpas” en Bélgica (flamenca), y el "Passeport Efficacité Énergétique” en Francia. BPIE, Building Renovation Passports. Customised roadmaps towards deep renovation and better homes, Brussels (2016) 4-6.

36 Propuesta número 4: "Se debe trabajar por mejorar los procedimientos administrativos e incorporar la industrialización en el proceso constructivo para situar en el mercado viviendas con calidad, eficientes energéticamente, pero a precios a los que la demanda pueda acceder". 


\subsection{Recursos normativos aplicados para desarrollar la sostenibilidad en el sector de la edificación}

La mayor parte de los grupos de interés $(82,4 \%)$ considera que la intervención en la edificación ha perseguido, principalmente, la aplicación de normas europeas y autonómicas, municipales o estatales de sostenibilidad, en este orden de importancia.

Como se puede observar en la figura 10, el Código Técnico de Edificación es la norma que más se utiliza $(70,6 \%)$ y, en menor medida, las normas de accesibilidad $(23,5 \%)$ y residualmente las normas municipales de suelo, vivienda, edificación y rehabilitación $(5,9 \%)$.

Figura. 10. Normativa aplicada para desarrollar la sostenibilidad

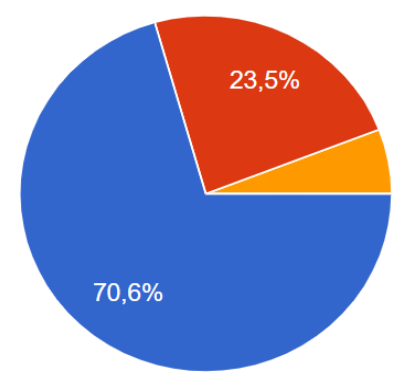

Código Técnico de la edificación

Accesibilidad de espacios

Normas municipales de suelo,

vivienda, edificación o rehabilitación

En la figura 11 se identifican las principales barreras para el buen desarrollo de la normativa estatal, autonómica o municipal, destacándose mayoritariamente la falta de flexibilidad del marco normativo $(52,9 \%) \mathrm{y}$, en segundo término, la falta de capacidad financiera $(23,5 \%)$ y la falta de incentivos $(17,6 \%)$.

Figura. 11. Barreras para el buen desarrollo de la normativa
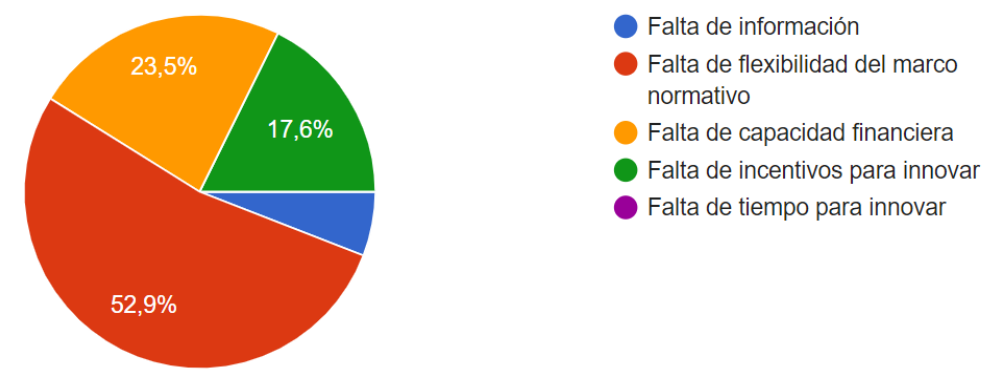

Como se puede apreciar en la figura 12, los principales factores que han propiciado la aplicación de la normativa estatal, autonómica o municipal han sido las exigencias de la administración (70,6\%), el interés de los consumidores $(17,6 \%)$ y el compromiso empresarial $(11,8 \%)$ y, en ningún caso, la búsqueda de incentivos económicos, ni la presión de las organizaciones ecologistas.

Propuesta número 15: "Reducir la Fiscalidad sobre la vivienda. Del precio total que una familia paga por una vivienda, un $25 \%$ se destina a pagar cargas tributarias correspondientes a los diferentes niveles de la administración durante el proceso productivo de la vivienda, porcentaje muy superior al de la media europea. Esta presión fiscal resulta muy elevada para un bien de primera necesidad, por lo que resulta imprescindible su reducción.

Además, en estos últimos años, se han incrementado las exigencias técnico-constructivas de la obra nueva, en aras de mejorar la eficiencia energética de los edificios, lo que conlleva un sobrecoste en la construcción de vivienda, que -en definitiva- redunda en un beneficio para toda la sociedad al rebajarse la factura energética del país. Por ello, se considera de interés que se establezcan bonificaciones fiscales ligadas a la calificación energética de los edificios.

También se precisa establecer el tipo de IVA reducido para las obras de rehabilitación de viviendas de particulares. Además, las ayudas y subvenciones no deberían tributar como incremento patrimonial dado que esto desincentiva la inversión y sería conveniente valorar la posibilidad de dar un tratamiento especial en materia de impuestos a los casos de reformas en viviendas adquiridas como consecuencia de una herencia" CEOE (2019): Informe sobre la Vivienda en España: propuestas de mejora, Madrid, pág. 1 y 4-5. Disponible en https://contenidos.ceoe.es/CEOE/var/pool/pdf/publications docs-file-678-la-vivienda-en-espana-propuesta-de-mejora.pdf [último acceso 24 de noviembre de 2019]. 
Figura. 12. Factores inductores de la aplicación de la normativa estatal
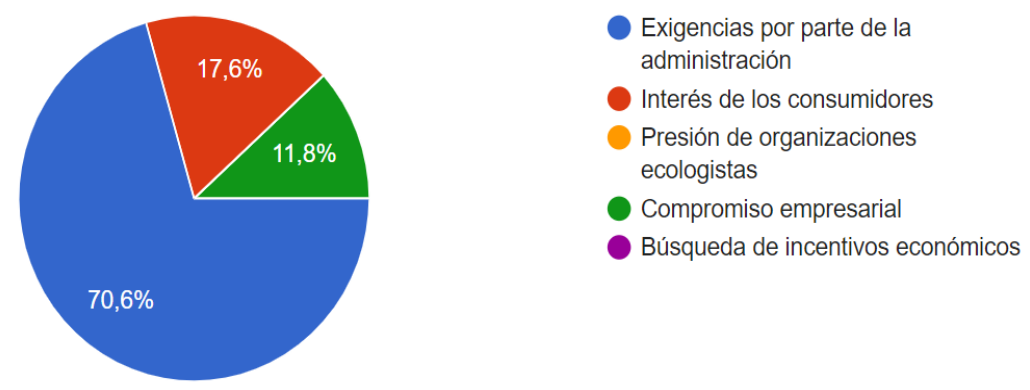

Por último, hay que señalar que un $64,7 \%$ de los grupos de interés señala que no ha introducido ninguna mejora, novedad o innovación adicional con respecto a las vigentes exigencias normativas de sostenibilidad en la edificación frente a un 35,3\% que afirma que sí lo ha hecho. Estos últimos evidencian que han actuado en cuestiones como las siguientes: acondicionamiento pasivo; uso de materiales de bajo impacto ambiental (aspectos que no se consideran en la normativa); estrategias Passivhaus, LEED \& BREEAM ES; sistemas constructivos y fuentes de energía; gestión de agua o promoción del empleo local ${ }^{37}$.

\subsection{Recursos de comunicación con la sociedad para el desarrollo de la sostenibilidad en el sector de la edificación}

Los grupos de interés que han participado en la encuesta han interactuado con otros agentes para el desarrollo de su actividad, un 53,3\% lo ha hecho con evaluadores de certificaciones y un $46,7 \%$ con asesores con formación técnica. En la figura 13 se puede apreciar cómo esta interacción ha servido para aportar principalmente asistencia en el desarrollo del proyecto (así lo manifiesta un 81,3\% de los encuestados) y minoritariamente mayores rendimientos ambientales de la edificación $(18,8 \%)$.

Figura. 13. Motivo de la interacción con los agentes en materia de certificación

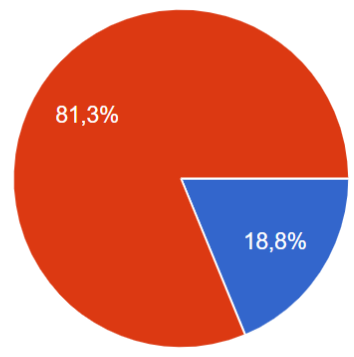

Mayores rendimientos ambientales de la edificación

Asistencia en el desarrollo del proyecto

Una gran mayoría de los grupos de interés encuestados $(85,7 \%)$ señalan que no existen campañas de información y sensibilización suficientes sobre la conveniencia de realizar estudios técnico-financieros de rehabilitación de edificios. Y sólo un 14,3\% estima que sí se realizan este tipo de campañas, pero promovidas por las propias empresas del sector. Estos datos llaman la atención, sobre todo en el contexto actual donde es importante fomentar los principios y los valores de desarrollo sostenible, para cumplir con los objetivos europeos y los requerimientos de los Objetivos de Desarrollo Sostenible de la ONU.

\section{Conclusiones}

A raíz de los resultados de esta investigación, queda patente que la sostenibilidad en el sector de la edificación es un proceso que se encuentra todavía en vías de desarrollo en España y que, por tanto, convendría implantar medidas que contribuyan a impulsar su implantación. A continuación, se exponen algunas posibles propuestas de mejora en este ámbito.

37 La rehabilitación, a menudo, la realizan pequeñas y medianas empresas muy ligadas al territorio, a su tejido social, y constituye una actividad intensiva en mano de obra. CEOE (2010) Informe de la Confederación española de organizaciones empresariales sobre Reforma y Rehabilitación, marzo de 2010, pág. 7-8. 
En primer lugar, la principal medida estratégica consistiría en generar políticas nacionales y municipales que incentiven la construcción sostenible, ya que sin la formulación de un plan que integre objetivos, líneas de acción y recursos es difícil promover la sostenibilidad en el sector de la edificación de una manera coherente y con visión de futuro. Además, estas políticas deberían diseñarse mediante un proceso participativo en el que tuvieran voz los diferentes agentes y grupos de interés del sector.

En segundo lugar, y en relación con la propuesta anterior, la sostenibilidad de la vivienda en España requiere de la asignación de recursos públicos y del apoyo necesario (subvenciones y ayudas) para garantizar su buen desarrollo. Principalmente porque los proyectos de construcción sostenible implican un coste añadido, que, a veces, es difícil de asumir, en solitario, por los ciudadanos y los grupos de interés. Por tanto, una medida de mejora ineludible es incrementar la ayuda pública en el sector de la edificación.

En tercer lugar, y también vinculado al tema de los recursos económicos, se debería motivar la solicitud de ayudas provenientes del Plan Estatal, ya que la mayor parte de los interesados recurren a las subvenciones de ámbito municipal. Además, se debería mejorar la transparencia económico-financiera de estas ayudas, difundiendo una información de calidad: completa, estructurada y comprensible. De este modo, se evitarían posibles confusiones entre las diferentes líneas de financiación.

En cuarto lugar, sería recomendable simplificar y flexibilizar el marco normativo en materia de sostenibilidad, así como el procedimiento de gestión de las certificaciones para que fuese más eficaz y eficiente.

En quinto lugar, se propone incorporar la figura del gestor técnico-financiero de rehabilitación con la finalidad que pueda realizar un control y seguimiento del impacto de las ayudas públicas en el desarrollo de la eficiencia energética de los edificios.

En sexto lugar, tanto las autoridades públicas como el sector privado podrían hacer mejor uso de los incentivos fiscales vinculando su otorgamiento a la obtención de determinadas certificaciones internacionalmente aceptadas. Así, por un lado, las empresas podrían disfrutar de tales incentivos, ejerciendo su responsabilidad social corporativa; y, por otro lado, los entes públicos podrían conceder incentivos más eficientes y justos, con un mejor control, comprobando que verdaderamente estén alineados con los objetivos de desarrollo sostenible en este campo.

En séptimo lugar, se debería promover la cultura de la sostenibilidad; impulsando iniciativas que contribuyan a transmitir una serie de principios y valores tanto a la sociedad, en general, como a los grupos de interés en el sector. Algunas de estas medidas, de carácter general, podrían consistir en formar a los estudiantes de educación primaria y secundaria, así como a los de educación superior -de manera reglada o no-.

En definitiva, todavía queda un largo camino por recorrer para instaurar una vivienda sostenible en España, pero esta investigación ofrece algunas posibles soluciones y recomendaciones para emprender el rumbo hacia la consecución de un objetivo ineludible para garantizar el buen desarrollo de nuestras sociedades actuales en un entorno sostenible y que, por ello, debe ser una de las prioridades en la agenda de nuestros gobiernos y administraciones públicas.

\section{Referencias bibliográficas}

Aguiar, N. (2015) Princípios cooperativos e benefícios fiscais. CIRIEC-España. Revista Jurídica, № 27, p. 10.

Alguacil Marí, P. et al. (2019) Informe sobre la Ley 5/2019, de 28 de febrero, de estructuras agrarias de la Comunitat valenciana: su impacto en cooperativas agroalimentarias. Cátedra Cooperativas Agroalimentarias: Cooperatives Agro-alimentàries de la Comunitat Valenciana.

Benito Hernández, S. y Zúñiga Durán, M.O. (2010) La inseguridad jurídica para los acreedores de las Sociedades Anónimas laborales ante el Real Decreto Ley 10/2008 de 12 de diciembre: mención a las sociedad constructoras y promotoras. REVESCO. Revista de Estudios Cooperativos, Segundo Cuatrimestre, No 102, pp. 54-78.

Berrocal Lanzarot, A.I. (2013) Análisis de la Ley 8/2013, de 26 de junio, de rehabilitación, regeneración y renovación urbanas. Actualidad Civil, No 9, pp. 969-1031.

Borgia Sorrosal, S. (2017) La vivienda: Impuestos y otras Políticas Fiscales: La experiencia Europea. Madrid: Fundación Impuestos y competitividad.

BPIE (2016) Building Renovation Passports. Customised roadmaps towards deep renovation and better homes, Bruselas, pp. 4-6.

Bueno Maluenda, M.C. (2017) Repensar la política fiscal sobre la rehabilitación de viviendas: propuesta de régimen fiscal para iniciativas cohousing, CIRIEC-España. Revista Jurídica, № 31, pp. 4 y ss.

Castellano Costa, J. (2015) Contribución a la sostenibilidad en la edificación mediante el desarrollo de una metodología simplificada para el cálculo de la eficiencia energética y de sostenibilidad de una vivienda. Tesis Doctoral dirigida por Joaquim de Ciurana Gay, A. Ribera Roget, Universitat de Girona.

CEOE (2019) Informe sobre la Vivienda en España: propuestas de mejora, Madrid, pág. 1 y 4-5. Disponible en https://contenidos.ceoe.es/CEOE/var/pool/pdf/publications docs-file-678-la-vivienda-en-espana-propuesta-demejora.pdf. 
CEOE (2010) La reactivación de la economía a través de un cambio en la reforma de viviendas y en la rehabilitación de edificios, marzo de 2010. Disponible en https://www.nasuvinsa.es/es/fondo-documental/la-reactivacion-de-laeconomia-traves-de-un-cambio-en-la-reforma-de-viviendas-y-en

European Heart Journal, Vol. 40, No 20, 21 de mayo de 2019, pp. 1590-1596, https://doi.org/10.1093/eurheartj/ehz135.

FEMP, Fundación casa que ahorra: Documento de recomendaciones sobre incentivos a la rehabilitación con criterios de eficiencia energética desde una perspectiva municipal. Disponible en http://femp.femp.es/files/3580-1587fichero/Documento_incentivos_rehabilitacion.pdf.

Gadea Soler, E., Atxabal Rada, A. e Izquierdo Muciño, M.E. (2014) Las cooperativas como alternativa económica: una visión de México y España. Madrid: Dykinson.

Grau Ruiz, M.A. (2017) La oportunidad del estímulo fiscal a la eficiencia energética en la rehabilitación de inmuebles para lograr la sostenibilidad en la vivienda. CIRIEC-España. Revista Jurídica, № 31, p. 4.

Lambea Rueda, A. (2015) Rehabilitación, Regeneración y Renovación urbana. Experiencias novedosas en Cooperativas de viviendas: rehabilitación y mediación. CIRIEC-España. Revista Jurídica, № 26, pp.121-156.

Lambea Rueda, A. (2015) Función social de la propiedad y nuevos límites a la Propiedad Horizontal: Efectos de la normativa de rehabilitación del sector inmobiliario. Revista de Derecho Privado, No 9/10, pp. 60-103.

Lambea Rueda, A. (2018) Tendencias presentes y futuras de ciudades y comunidades sostenibles y viviendas colaborativas a través de plataformas digitales. Revista Crítica de Derecho Inmobiliario, No 767, pp. 1231-1285.

Lucas Durán, M. (2017) Aspectos tributarios del cohousing o co-vivienda. CIRIEC-España. Revista Jurídica, Nº 31, p. 6.

Martínez Vargas, J., Carmona Ibañez, P. y Pozuelo Campillo, J. (2015) La presión fiscal en las cooperativas: una valoración por tamaños, comunidades y sectores para el período 2008-2011. REVESCO. Revista de Estudios Cooperativos, Tercer Cuatrimestre, № 119, pp. 132-158. DOI: 10.5209/rev_REVE.2015.n119.49070.

Merino, S. y Extezarreta, A. (2014) Las cooperativas de vivienda como alternativa al problema de la vivienda en la actual crisis económica. REVESCO. Revista de Estudios Cooperativos, Tercer Cuatrimestre, No 113, pp. 92-112. DOI: 10.5209/rev_REVE.2014.v113.43382.

Milà Rafel, R. (2014) Promoción inmobiliaria, autopromoción y cooperativas de viviendas. Navarra: Thomson ReutersAranzadi.

Ortale, M. (2014) Una propuesta para una política social de vivienda inconclusa. La construcción del espacio público y privado y el cooperativismo como claves para su diseño". Revista de trabajo social y ciencias sociales, $\mathrm{N}^{\mathrm{o}} 72, \mathrm{pp}$. 11.

Pastor Del Pino, M.C. (2016) Las cooperativas como sujetos de protección fiscal. CIRIEC-España. Revista Jurídica, N 28, p. 28.

Robles, C. e Izquierdo, M.E. (2014) Las cooperativas como alternativa económica: una visión de México y España. Madrid: Dykinson

Romero Civera, A. y Marí Vidal, S. (2015) Algunos aspectos críticos en la aplicación del impuesto de sociedades a las cooperativas según el régimen fiscal de cooperativas. La necesidad de su reforma. REVESCO. Revista de Estudios Cooperativos, Segundo Cuatrimestre, No 118, pp. 7-30. DOI: 10.5209/rev_REVE.2015.v118.48709.

Rua, M. J. y López Mesa, B. (2012) Certificación energética de edificios en España y sus implicaciones Económicas. Informes de la Construcción, Vol. 64, N 527, p. 307.

Tribunal de Cuentas de la Unión Europea (2018) Contaminación atmosférica: nuestra salud no tiene todavía la suficiente protección, Informe Especial No 23. DOUE C 324/05, 13.9.2018.

Vargas Vasserot, C., Gadea Soler, E. y Sacristán Bergia, F. (2015) Derecho de las sociedades cooperativas. Madrid: La Ley.

VVAA (2013) 40 años de historia de las empresas de participación. Dir. Lejarriaga, G; Muñoz García, A. Ed. Verbum

VVAA (2013) Economía social y derecho. Problemas jurídicos actuales de las empresas de economía social. Dir/coord: Gómez Manresa, F. y Pardo López M. Comares Granada.

VVAA (2014) Las cooperativas de viviendas en la comunidad valenciana. Dir. Gemma Fajardo García (Coordinación). ED. Ciriec-España/Generalitat Valenciana. 